\title{
Pharmacist review changed more repeat prescriptions for elderly patients than usual general practice review
}

Zermansky AG, Petty DR, Raynor DK, et al. Randomised controlled trial of clinical medication review by a pharmacist of elderly patients receiving repeat prescriptions in general practice. BMJ 2001 Dec 8;323:1340-3.

\section{QUESTION: In elderly patients who receive repeat prescriptions, is a clinical review of medications by a pharmacist more effective than usual general practice review for increasing medication changes and reducing costs?}

Design

12 month randomised \{allocation concealed*i†, \{unblinded $\}+,{ }^{*}$ controlled trial.

\section{Setting}

4 general practices in Leeds, UK.

\section{Patients}

1188 patients who were $\geq 65$ years of age (mean age $74 \mathrm{y}$, $56 \%$ women); were receiving $\geq 1$ drug on repeat prescription as of 1 June 1999; and were from a general practice in which prescribing costs were average and that had $\geq 4$ partners, computerised repeat prescribing, and no previous or current clinical pharmacist involvement. Patients were excluded if they lived in nursing or residential homes, had a terminal illness, or were enrolled in clinical trials. Follow up was $95 \%$.

\section{Intervention}

608 patients were allocated to pharmacist review, which had 3 components. In stage 1 , the pharmacist evaluated the patients; their illnesses; and their medications, including adherence. In stage 2, the pharmacist evaluated the patients' medication regimen in terms of need for ongoing drugs, side effects, inadequate treatment, and cost. In stage 3, if necessary, the pharmacist implemented changes. Any substantial changes were made with the cooperation of a general practitioner (GP). 580 patients were allocated to usual care from their GP, including a review of medications according to the practice's normal custom.

\section{Main outcome measures}

Source of funding: NHS Research and Development National Coordinating Centre for Health Technology Assessment.

For correspondence: Dr A G Zermansk) University of Leeds, Leeds, UK.

arnoldz@easynet.co.uk. (table). The increase in mean medication cost per patient over 28 days was less in the pharmacist-review group than in the usual-care group (change from baseline $£ 1.80$ v $£ 6.52,95 \%$ CI for the $£ 4.72$ difference $£ 2.41$ to $£ 7.04$ ).

\section{Conclusion}

In elderly patients who receive repeat prescriptions, a pharmacist review of medications resulted in more prescription changes but fewer medications prescribed and lower medication costs than did usual general practice review.

*See glossary.

$\uparrow$ Information provided by author.

\section{COMMENTARY}

Are consultations with a clinical pharmacist effective for reviewing the types, dosages, and numbers of medications prescribed to elderly patients? Unfortunately, the limitations of the study by Zermansky et al do not allow a clear answer.

About half the patients asked to participate declinedperhaps a vote of confidence in their GPs? Those recruited tended to be younger, male, and taking fewer drugs than the non-participants. How representative of the elderly population are such volunteers?

The pharmacist involved in the study was an academic research pharmacist, which also calls into question the study's generalisability. To show the effects of clinical reviews by pharmacists, a number of "regular" community pharmacists would need to be trained and studied because presumably they would better typify those who would be providing such a service.

Similarly, how representative were the GPs included in the study? The practices were selected from a list of those with $\geq 4$ partners, computerised repeat prescribing systems, and prescribing costs close to average. These may not be your average local general practices, but even so, less than half the usual-care group actually received a documented review of their prescriptions over the course of a year.

What of the results? The differences found may be statistically significant, but given the relatively wide confidence intervals, are they clinically significant? Perhaps compared with the efforts of a research pharmacist and in the midst of the competing demands of primary care, the GPs were not doing too badly at all.

A larger project involving more practices and pharmacists is needed to clarify the practicality, costs, and benefits. Perhaps we should wait for the results of such a study before jumping to too many conclusions about the potential advantages of a system of clinical medication review by pharmacists.

Anthony Dixon, MB, ChB University of Hong Kong Hong Kong, China 